\title{
The Role of Technical Innovation and Sustainability on Energy Consumption: A Case Study on the Taiwanese Automobile Industry
}

\section{Chao-Wu Chou ${ }^{1}$, Wen-Chih Liao ${ }^{1}$, Simon Wu ${ }^{2}$ and Hui-Ming Wee ${ }^{3, *}$}

1 Department of Business Administration, National Taiwan University of Science and Technology, Taipei 10607, Taiwan; E-Mails: mikechou916@gmail.com (C.-W.C.); fumi@mail.ntust.edu.tw (W.-C.L.)

2 Vigor Management Technology Academy, Vigor Management Technology Group, C7, Far Eastern Part, Yu Yao Economic Development Section, Ningbo 315211, Zhejiang, China; E-Mail: wusq@vmta.com

3 Department of Industrial and Systems Engineering, Chung Yuan Christian University, 200 Chung Pei Rd., Chungli 32023, Taiwan

* Author to whom correspondence should be addressed; E-Mail: weehm@cycu.edu.tw; Tel.: +886-3-265-4409; Fax: +886-3-265-4499.

Academic Editor: K. T. Chau

Received: 8 May 2015 / Accepted: 9 June 2015 / Published: 30 June 2015

\begin{abstract}
The impact of global warming and climate change is one of the most critical challenges of the 21 st century. The greenhouse effect caused by technological development and industrial pollution has accelerated the speed of global warming. The continuous improvement in automobile energy consumption is one of the most effective ways to reduce global warming. A comparative analysis is proposed to examine the various automobiles that utilize technological innovation to improve their energy consumption. Their contribution to $\mathrm{CO}_{2}$ emissions is then investigated. This study focuses on technical innovation and output power of a conventional engine. The results indicate that innovative engines (such as the Ford turbo petrol/diesel engine, the EcoBoost/TDCi) have improved energy consumption and reduce $\mathrm{CO}_{2}$ emissions. In addition, the Toyota hybrid vehicles have also improved energy consumption and reduced greenhouse gases emissions.
\end{abstract}

Keywords: global warming; energy; technical innovation; sustainable development 


\section{Introduction}

The impact of global warming and climate change on animal, plant and human civilization has become one of the most critical issues in the 21 st century. There is a close relationship existing between climate change and human civilization [1,2]. Human civilizations can be divided into two categories: technological civilizations and humanistic civilizations. Humanistic civilization has played an essential role in the last 5000 years. However, civilization and technological developments have disastrous consequences for the future generations. The rapid development of technological civilization has changed the role of mankind from a passive to an active role. The increase in disasters caused by typhoons, floods, landslides, earthquakes, and tsunamis reflect that humans are not in control of their destiny.

In attaining sustainable development, a sustainable energy policy plays an important role [3] in increasing energy efficiencies and in developing the renewable energy supply [4,5]. Moreover, energy is a vital input for social and economic development [6]. In order to encourage the development of a sustainable enterprise, we use a comparative analysis approach to examine various Taiwanese automotive products, based on the performance of their innovative technological engines. Their contributions to fuel consumption and emissions of the greenhouse gases and carbon dioxide $\left(\mathrm{CO}_{2}\right)$ are then compared. The comparison is based on the horsepower and torque generated by the unit engine displacement (measured in cubic centimeters (cc)), and their impact on fuel consumption and $\mathrm{CO}_{2}$ emission. This study focuses on the technical innovation in conventional engines and their output power. Technical innovation is explored by examining a Ford turbo petrol engine (EcoBoost engine), and the output power is explored by examining the power consumption of a Toyota hybrid vehicle (Hybrid Prius). Figure 1 shows the research framework.

\section{Literature Review}

To improve the quality of life with a superior living environment, mankind continues to use more natural resources. The rapid population growth and continuous advances in technology accelerate deforestation, water pollution, mudslides, air pollution, holes in the ozone layer, biodiversity reduction, desertification, and global climate change [2,7].

Since the start of the Industrial Revolution in 1750, emissions of $\mathrm{CO}_{2}$, nitrous oxide $\left(\mathrm{N}_{2} \mathrm{O}\right)$, methane $\left(\mathrm{CH}_{4}\right)$, chlorofluorocarbons, and other greenhouse gases have increased. The impact has affected the Earth, as well as the atmosphere, resulting in global warming. Scientists have concluded that excessive human development has caused drastic climate changes. Since the 1980s, the rapid rise in the average global temperature, unusual weather and climate phenomena (such as El Niño and La Niña) has caught the attention of the world on climate change issues [8,9]. To reduce the greenhouse gases emission and improve global warming, the United Nations Framework Convention on Climate Change (UNFCCC) has committed its State Parties to adopt the Kyoto protocol in 1997 and have entered into force on 16 February 2005 [10]. Feroz et al. [11] conducted a study on the relationships between environmental production efficiency rankings and the ratification status of the United Nations Organization's Kyoto Protocol participants. Their findings show that the nations that have ratified the Kyoto Protocol are more likely to be environmentally production-efficient as compared to the nations that have not ratified the treaty. 


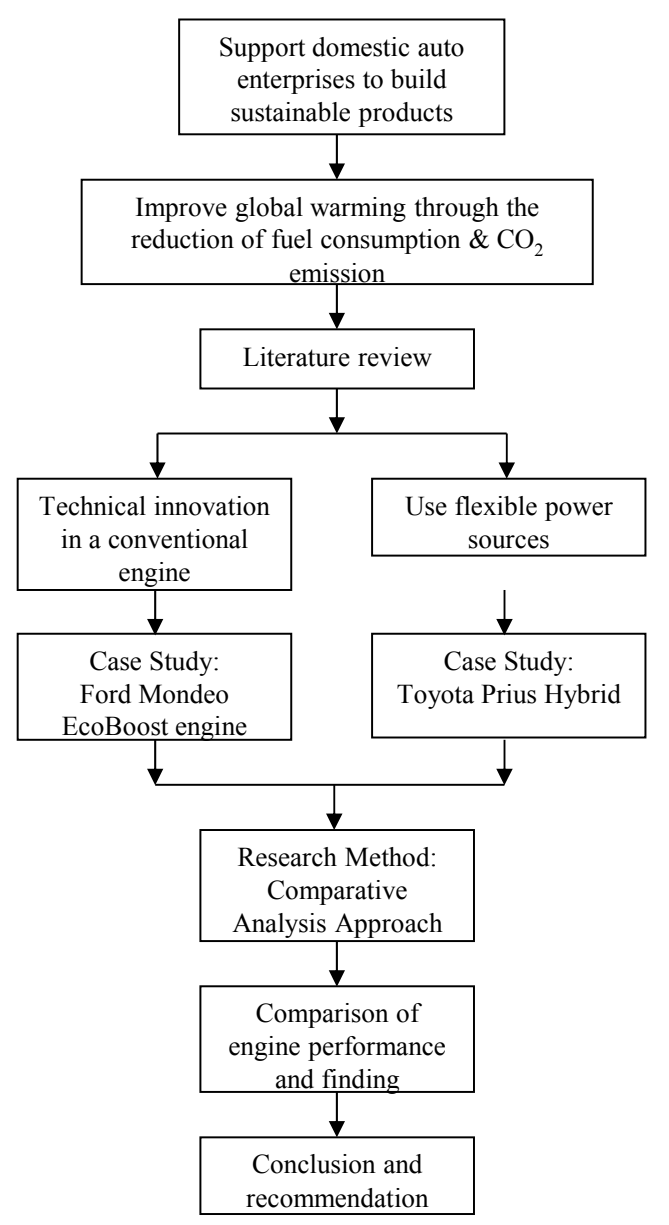

Figure 1. The research framework.

\subsection{What Is Global Warming?}

Climate change has become a crucial and widely debated issue. The approaches used to reduce global carbon emissions are the contraction and convergence approach. Under these approaches, all countries should participate in global emission reduction by quantifying their emission limits. The scientific definition of global warming is "a tendency for the globe to warm up over a given period of time". Many scientific studies have focused on climate change; they concluded that the average global temperature is increasing [12-15].

\subsection{Causes of Global Warming}

Global warming is primarily caused by excessive amounts of $\mathrm{CO}_{2}$ in the atmosphere. The $\mathrm{CO}_{2}$ acts as a blanket, trapping heat and warming the planet. As we burn fossil fuels, such as coal, oil, and natural gas, $\mathrm{CO}_{2}$ accumulates and overloads our atmosphere. Certain waste management and agricultural practices aggravate the problem by releasing other potent global warming gases, such as methane and nitrous oxide. Lallanilla [15] discussed the meaning of the greenhouse effect, and Panwar et al. [16] made a review on the scope of $\mathrm{CO}_{2}$ mitigation through solar cooker, water heater, dryer, biofuel, and improved cook stoves. 


\subsection{What Are Greenhouse Gases?}

Behind the struggle to address global warming and climate change lays an increase in greenhouse gases in the atmosphere. Greenhouse gases are any gaseous compound in the atmosphere that is capable of absorbing infrared radiation, thereby trapping and holding heat in the atmosphere. By increasing the heat in the atmosphere, greenhouse gases are responsible for the greenhouse effect, which ultimately leads to global warming. The most significant greenhouse gases are water vapor, $\mathrm{CO}_{2}, \mathrm{CH}_{4}$, and $\mathrm{N}_{2} \mathrm{O}$. Various greenhouse gases have different impacts and contributions to the greenhouse effect $[17,18]$.

To attain sustainable development and develop a sustainable energy policy, we conducted a case study of the Taiwanese automobile market. Two approaches are investigated to reduce the greenhouse gases and increase the energy efficiency; we also investigate the alternative energy sources to replace the fossil fuels. Technical innovation and output power improvement are considered to improve the efficiency of the conventional engines and the use of alternative energy.

\subsection{Technical Innovations}

Wee et al. [5] reviewed the sources of renewable energy and investigated the renewable energy supply chain, renewable energy performance, and the barriers and strategies to its development. This study focuses on the last component; that is the strategies to renewable energy development. Recently, industrial energy efficiency improvements have focused on efficiency improvements rather than on the integration of renewable sources [12].

Harabi [19] stated that technical innovations include process innovation and product innovation. Process innovation generally aims to reduce cycle time (lead time), and product innovation focuses on producing superior product or service performance. Gort and Klepper [20] proposed that product innovation consists of two parts: the technical development of new products and market introduction of new products.

\subsubsection{Turbocharger}

A turbocharger, derived from Greek $\tau u ́ \rho \beta \eta$ (turbulence), is a turbine-driven forced induction device that increases the efficiency of an engine by allowing it to produce more power than its size. A turbocharged engine is more powerful and efficient than a naturally aspirated engine, because the compressor forces more air into the combustion chamber than the atmospheric pressure alone. Compared to a mechanically driven supercharger, turbochargers tend to be more efficient, but less responsive. A twin-charger refers to an engine with a supercharger and a turbocharger [21].

\subsubsection{Hybrid Vehicles}

A hybrid vehicle is a vehicle that uses two or more distinct power sources. The most commonly referred term is the hybrid electric vehicle that combines an internal combustion engine (ICE) and one or more electric motors. All hybrids exhibit the ability to generate electric current, store this current in a large battery, and use the current to drive a car. Hybrids capture electrical energy produced by a regenerative braking system, and their engines can also power a generator. Hybrids can conserve 
energy by shutting down the ICE when the vehicle is parked, idled at a red traffic light, jammed in traffic, or when the electric motor energy is sufficient to power the vehicle without assistance from the ICE. Hybrids exhibit regenerative braking systems that generate electric power to charge the batteries. When a driver applies the brakes, the electric motor turns into a generator, and the magnetic drag slows the vehicle. For safety, they also include a normal hydraulic braking system that can stop the car when regenerative braking is insufficient. The maintenance and repair of the hybrid and normal braking systems is the same, except the brake pads tend to last much longer because they are not used as much. In fact, if someone drives a hybrid consciously, he/she will seldom use the disc brakes, and may never have to change the pads. Regenerative brakes capture energy and turn it into electricity to charge the battery that provides power to an electric motor [22,23].

\subsection{Sustainable Development}

Energy resources and their utilization intimately relate to sustainable development [3]. The sustainable development strategies typically involve three major technological changes: energy savings on the demand side, efficiency improvements in the energy production, and replacement of fossil fuels by various sources of renewable energy [24]. Sustainable development is a principle for organizing human life on earth without undermining the natural resources and the environment. As early as the 1970s, sustainability was used to describe an economy "in equilibrium with basic ecological support systems". Scientists in many fields have stated that limits to growth exist, and economists have presented alternatives to address concerns regarding the impact of expanding human development on Earth [25-27].

The term sustainable development became popular after it was used by the Brundtland Commission in its 1987 report, Our Common Future [28]. In the report, the commission coined what has become the most frequently quoted definition of sustainable development: "Development that meets the needs of the present without compromising the ability of future generations to meet their own needs." The concept of sustainable development is usually separated into three constituent domains: environmental sustainability, economic sustainability, and social sustainability [29]. However, many other possible ways to delineate the concept have been suggested. For example, the circles of sustainability approach use the four domains of economic, ecological, political, and cultural sustainability. This corresponds with the United Cities and Local Governments suggestion that culture is the fourth domain of sustainability [25-27].

\section{Research Method}

Based on the technical innovation of automobile engines, a comparative analysis was suggested by Butler and King [30] to examine the various automotive products. Their contribution to fuel consumption and emissions of the greenhouse gases are then compared. The comparison was based on the generated horsepower and torque produced by the unit engine displacement (measured in cc).

The comparative analysis approach is a qualitative comparative analysis (QCA) method. The technique was originally developed by Ragin in 1987 [31]. It is used for analyzing datasets by listing and counting all the combinations of variables observed in the dataset. The rules of logical inference are used to determine which descriptive inferences or implications are supported by the data. 
This reduced minimal set of inferences is called the prime implicates or descriptive inferences, which are derived from the data by using QCA. This method is used to ensure that all the possible combinations of variables are considered; the method is usually used in social science, and is based on the binary logic of Boolean algebra [30,32].

\section{Voluntary Carbon Dioxide Reduction Agreement (Taiwanese Environmental Protection Administration)}

On December 28, 2010, the Taiwanese Environmental Protection Administration (EPA) signed "the voluntary carbon dioxide reduction agreement for new vehicles". Six automakers from domestic and international companies cosigned the environmental agreement to reduce the total volume of $\mathrm{CO}_{2}$ emissions for all vehicles sold after 2015 by $10 \%$ to $15 \%$. This agreement was made to encourage voluntary $\mathrm{CO}_{2}$ reduction to reduce global warming. Signatories included BMW, Ford Motor Company, Honda Taiwan, China Motor, Hyundai, and Mercedes-Benz. The voluntary carbon emission reductions agreement targets at reducing $\mathrm{CO}_{2}$ emissions to $163 \mathrm{~g} / \mathrm{km}$, or $15 \%$ less than the 2009 levels [33].

By the end of 2013, two domestic automakers reached their reduction targets, and the EPA awarded them medals in recognition of their efforts. The largest emission reduction was achieved by Toyota (25\%), followed by Ford Motor, Taiwan (19\%). These reductions were both more than the 15\% reduction target. A major contribution of Toyota is the introduction of hybrid cars to promote low-carbon vehicles $\left(\mathrm{CO}_{2} \leq 120 \mathrm{~g} / \mathrm{km}\right)$. Ford Motor was the first vehicle assembly plant to sign the voluntary $\mathrm{CO}_{2}$ reduction agreement, and its major contribution was producing vehicles with turbocharged engines (EcoBoost/TDCi); it reduced $\mathrm{CO}_{2}$ emissions significantly. After the promotion of the voluntary $\mathrm{CO}_{2}$ reduction agreement by the Taiwanese EPA, 13 motor companies (including international and domestic companies) signed the agreement to reduce $\mathrm{CO}_{2}$ emissions from their cars by an average of $11 \%$ from the 2009 value [33].

\section{Comparison of Engine Performance in the Taiwanese Automobile Market}

To compare engine performance in the Taiwanese automobile market, we examined the technical innovation of a turbocharging petrol engine (the Ford EcoBoost) [34] and a hybrid vehicle (the Toyota Prius) [35]. Other brands were used for comparative analysis [36-38].

\subsection{Ford EcoBoost Engine}

Ford Lio Ho (FLH) or Ford Motor is a subsidiary of Ford Motor Company in Taiwan. To reduce its $\mathrm{CO}_{2}$ emissions by $10 \%$ to $15 \%$ by 2015 [34], FLH introduced the advanced Ford EcoBoost engine, with a $20 \%$ improvement in fuel consumption and a $15 \%$ reduction in $\mathrm{CO}_{2}$ emissions. The engine met the requirements of the Ford Drive Green vision, and implemented the sustainable development concept of Ford's global objectives. Figure 2 shows the $\mathrm{CO}_{2}$ emission reduction model for Ford's global vehicles, which transforms the $\mathrm{CO}_{2}$ emission target into a product plan (see Figure 3); sets short-, medium-, and long-term sustainable development strategies (see Figure 4); and gradually introduces engines that are innovative technically. Figure 5 shows the turbocharged EcoBoost engine [34]. 


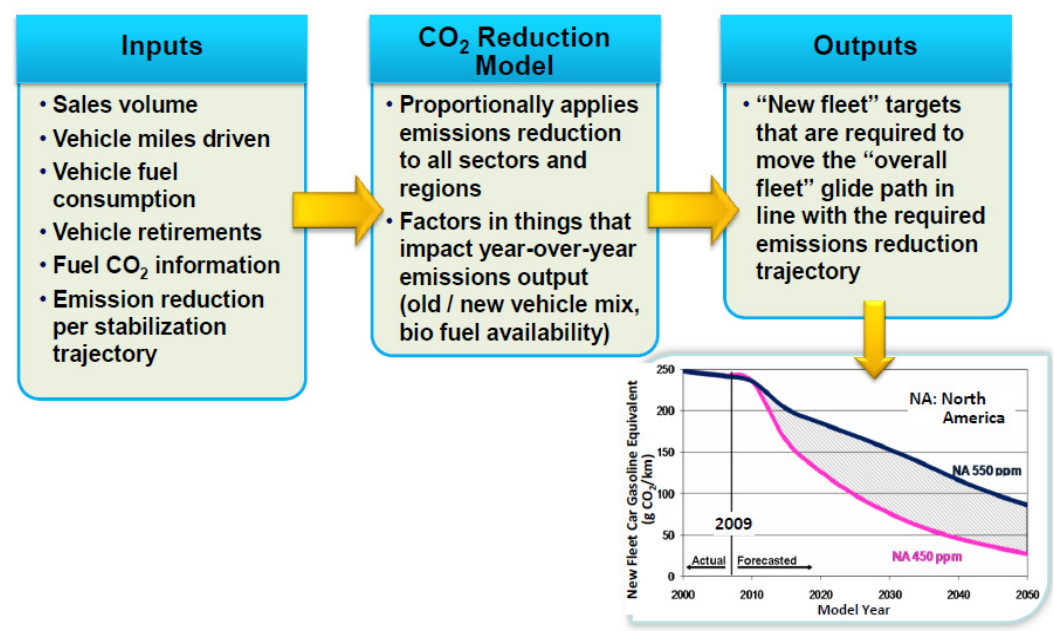

Figure 2. The $\mathrm{CO}_{2}$ emissions reduction mode for Ford's global vehicles. Source [34].

We conducted a comparative analysis of the conventional domestic vehicle engine performance to compare them with the Ford EcoBoost. Horsepower and torque were the major performance indicators used to measure engine output. Table 1 shows the comparison of engine displacement $v s$. horsepower and torque in local market for January 2014. The data indicated that the EcoBoost engine exhibited superior horsepower and torque performance than domestic vehicles with conventional engines. This demonstrated that the EcoBoost engine exhibits improved energy-saving and carbon reduction performance, reflecting a reduction in fuel consumption and $\mathrm{CO}_{2}$ emission.

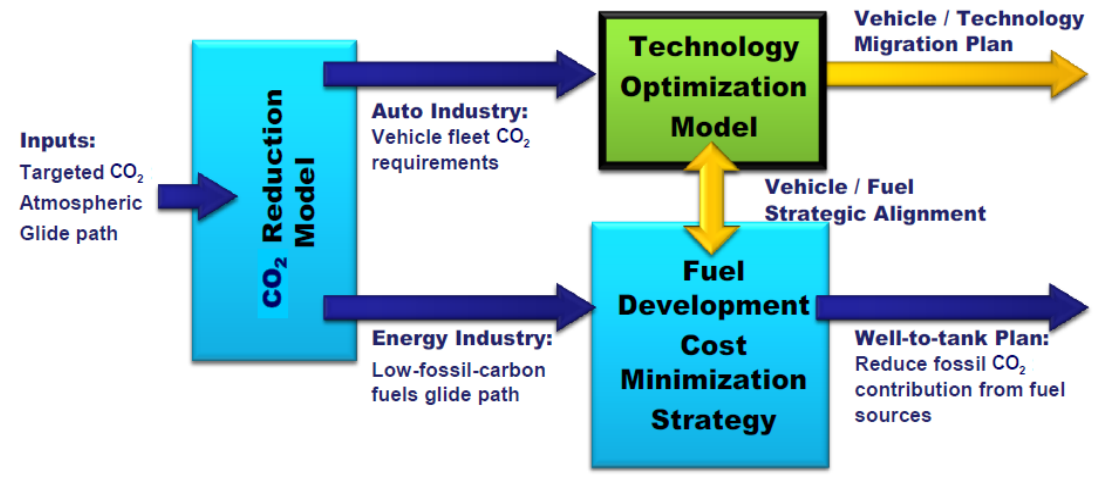

Figure 3. Transforming the $\mathrm{CO}_{2}$ emission target into product plan. Source [34].

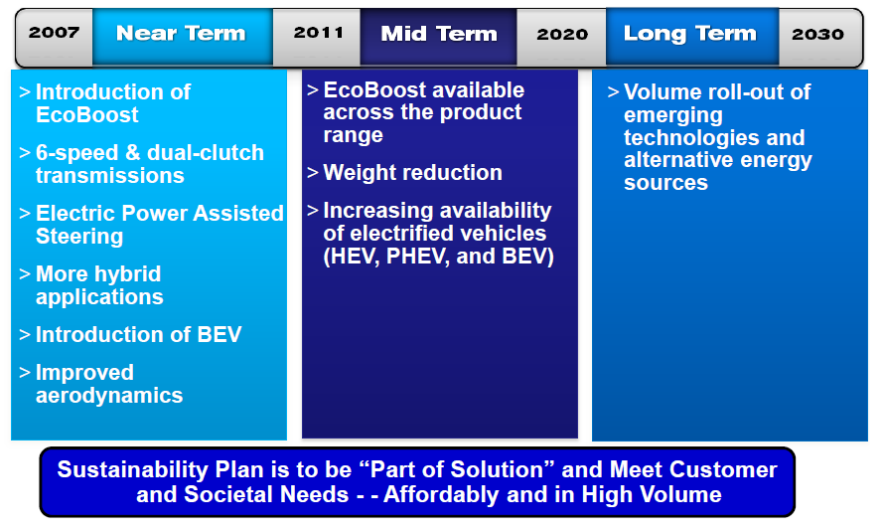

Figure 4. The global sustainability strategy. Source [34]. 

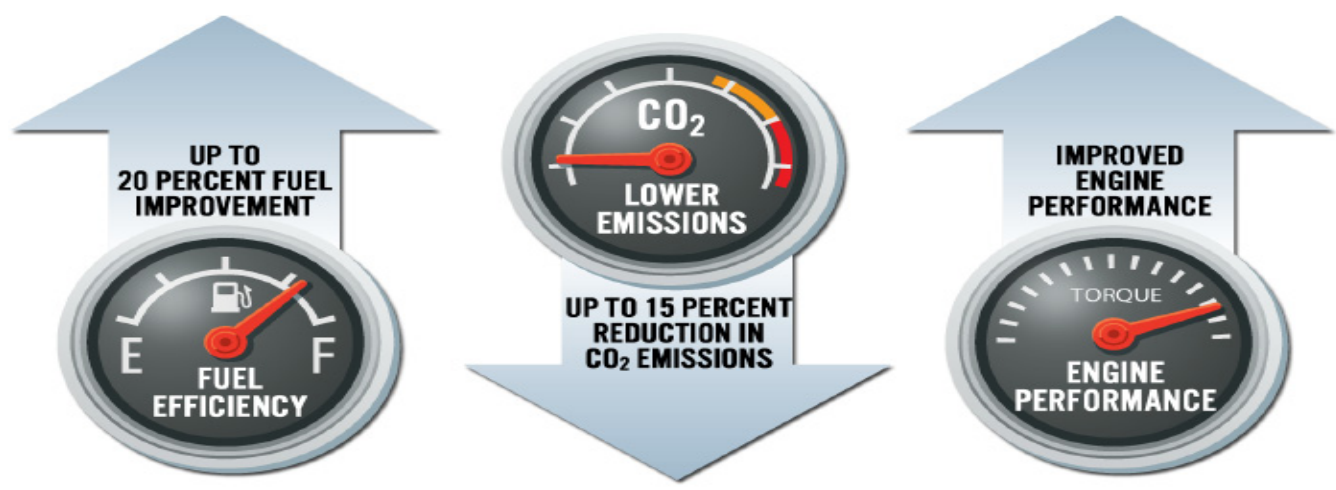

Figure 5. The performance of turbocharged EcoBoost engine. Source [34].

To demonstrate the positive relationship between a high-performance engine and low energy consumption and reduced greenhouse gases $/ \mathrm{CO}_{2}$ emissions, we summarized data from the Mechanical Department of the Industrial Technology Research Institute of Taiwan (ITRI). Figures 6 and 7 show the graphs of fuel consumption and $\mathrm{CO}_{2}$ emission tests for the passenger cars.

Table 1. The comparison of engine displacement $v s$. horsepower and torque in local market.

Data source: Ford, Toyota, Nissan, Mitsubishi, and Honda official website [34-38].

\begin{tabular}{|c|c|c|c|c|c|c|c|c|c|}
\hline Brand & Model & $\begin{array}{l}\text { Displacement } \\
\text { (cc) }\end{array}$ & & $\begin{array}{l}\text { mum } \\
\text { PM } \\
\text { pm) }\end{array}$ & $\begin{array}{r}\text { Ma } \\
\text { Tore } \\
\text { (kg. }\end{array}$ & $\begin{array}{l}\text { mum } \\
\text { /RPM } \\
\text { /rpm) }\end{array}$ & $\begin{array}{c}\text { HP/displacement } \\
\text { (hp/cc) }\end{array}$ & $\begin{array}{c}\text { Torque/displacement } \\
\text { (kg.m/cc) }\end{array}$ & $\begin{array}{l}\text { Data } \\
\text { source }\end{array}$ \\
\hline \multirow{2}{*}{ Ford } & $\begin{array}{l}\text { Mondeo } \\
\text { EcoBoost }\end{array}$ & 1999 & 240 & 6000 & 34.7 & 3500 & 0.12 & 0.017 & \multirow{2}{*}{ [34] } \\
\hline & $\begin{array}{c}\text { Kuga } \\
\text { EcoBoost }\end{array}$ & 1998 & 242 & 5500 & 35.7 & 3000 & 0.12 & 0.018 & \\
\hline \multirow{2}{*}{ Toyota } & Camry & 1998 & 148 & 6000 & 19.4 & 4100 & 0.07 & 0.010 & \multirow{2}{*}[35]{} \\
\hline & Camry & 2494 & 181 & 6000 & 23.6 & 4100 & 0.07 & 0.009 & \\
\hline \multirow{2}{*}{ Nissan } & Teana & 1997 & 134 & 5600 & 19.4 & 4400 & 0.07 & 0.010 & \multirow{2}{*}[36]{} \\
\hline & Teana & 2496 & 180 & 6000 & 23.2 & 4500 & 0.07 & 0.009 & \\
\hline \multirow{2}{*}{ Mitsubishi } & Outlander & 2359 & 172 & 6000 & 24.0 & 3900 & 0.07 & 0.010 & \multirow{2}{*}[37]{} \\
\hline & Zinger & 2378 & 159 & 6200 & 22.6 & 4300 & 0.07 & 0.010 & \\
\hline \multirow{2}{*}{ Honda } & Accord & 2356 & 180 & 6400 & 25.0 & 3500 & 0.08 & 0.011 & \multirow{2}{*}{ [38] } \\
\hline & CRV & 1997 & 155 & 6500 & 19.4 & 3500 & 0.08 & 0.010 & \\
\hline
\end{tabular}

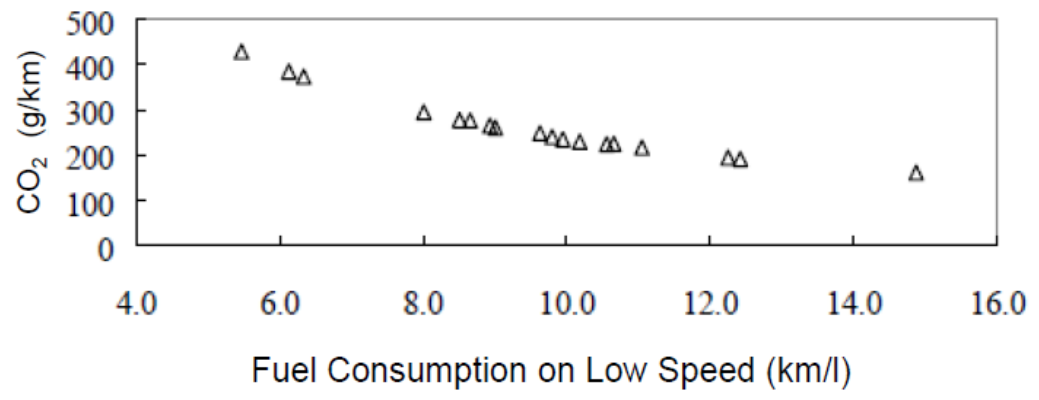

Figure 6. The fuel consumption vs. $\mathrm{CO}_{2}$ emission on low speed. Source [39]. 


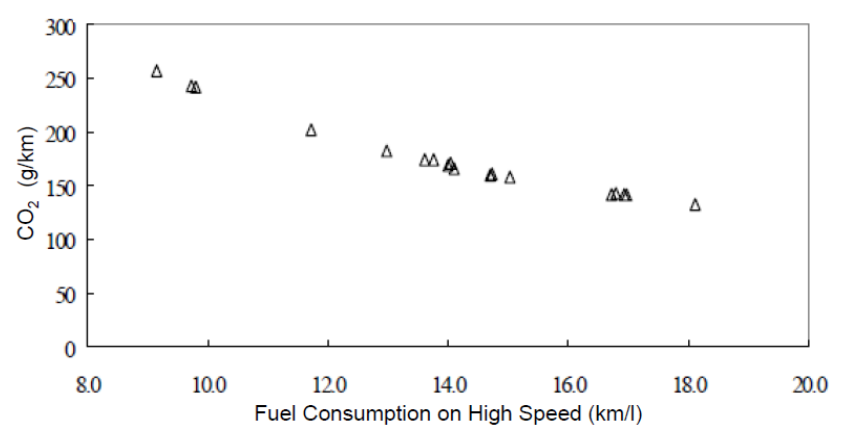

Figure 7. The fuel consumption vs. $\mathrm{CO}_{2}$ emission on high speed. Source [39].

\subsection{Toyota Hybrid}

In 1997, Toyota launched a hybrid system car that has caught the attention of the world. The first batch of mass-produced hybrid system cars, the Prius Hybrid, was sold in more than 40 countries and regions around the world. In 2001, its biggest markets were Japan and North America. In the beginning of 2009, more than 600,000 Prius Hybrids had been sold in the USA, and by April 2011, over one million Prius Hybrids had been sold [40-42]. According to data from the US Environmental Protection Agency, the Prius Hybrid is the most economical car in the USA [35,43]. In 2010, its fuel consumption was as follows: low speed, $51 \mathrm{mpg}-\mathrm{US}(4.6 \mathrm{~L} / 100 \mathrm{~km} ; 61 \mathrm{mpg}$-imp; $21.7 \mathrm{~km} / \mathrm{L})$; high speed, $48 \mathrm{mpg}$-US (4.9 L/100 km; $58 \mathrm{mpg}$-imp; $20.4 \mathrm{~km} / \mathrm{L})$; and average speed, $50 \mathrm{mpg}$-US (4.7 L/100 km; 60 mpg-imp; $21.3 \mathrm{~km} / \mathrm{L}$ ) [33,44].

Figures 8-11, respectively, show the components, the high-performance capabilities, the driving force characteristics and the relationship between torque and speed of the Prius Hybrid [35].

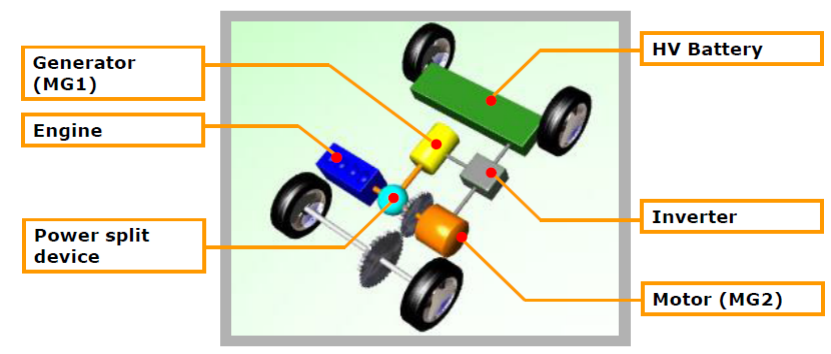

Figure 8. The components of the Prius Hybrid. Source [35].

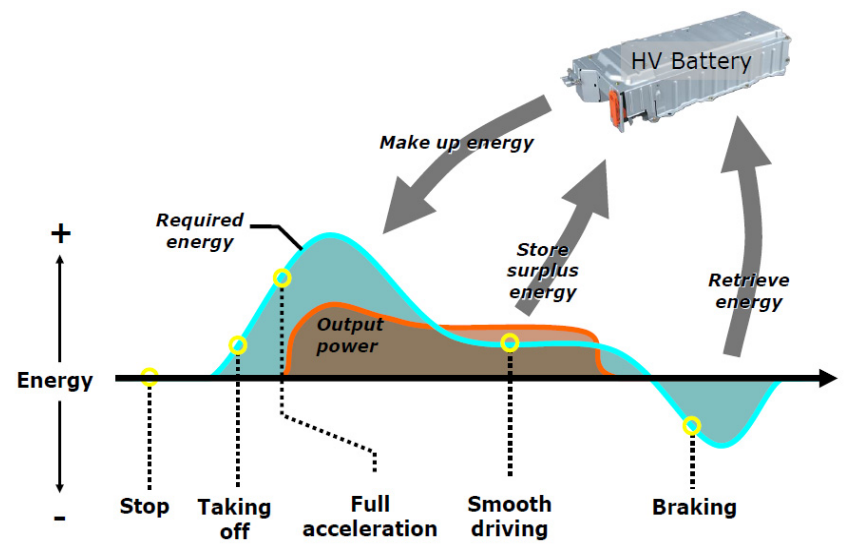

Figure 9. The high performance of the hybrid system. Source [35]. 


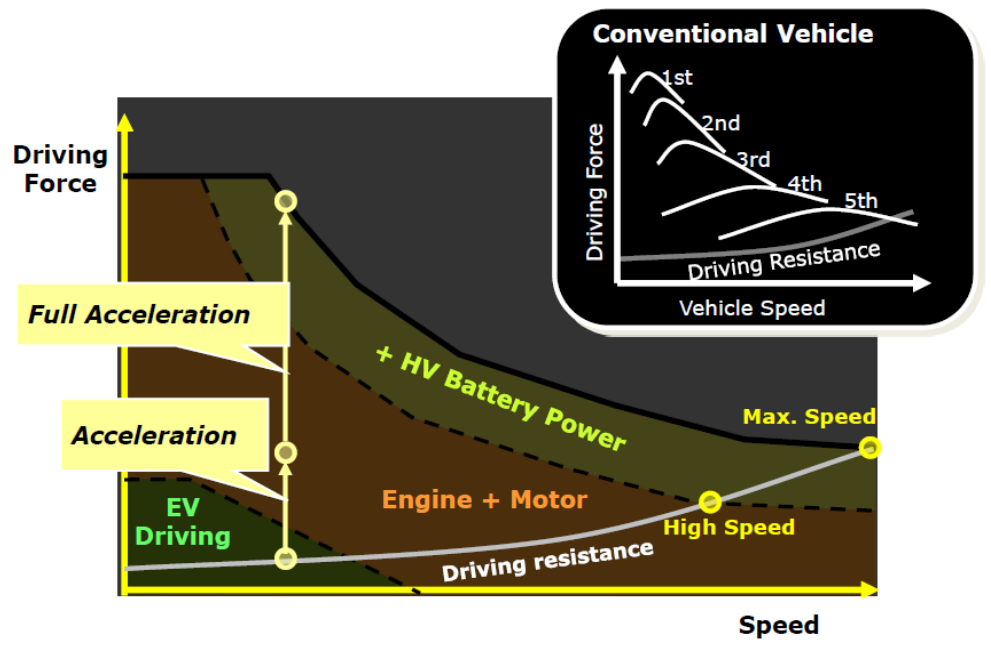

Figure 10. Driving force vs. speeds for the hybrid system. Source [35].
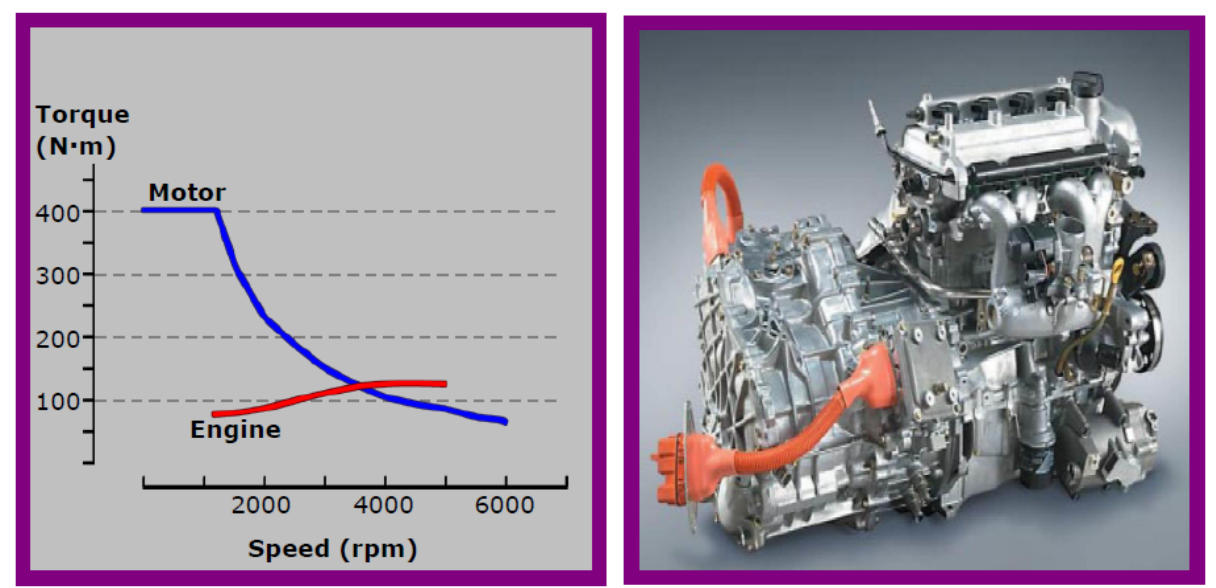

Figure 11. The relations between torque and speed for the hybrid system. Source [35].

Based on the data collected in Taiwan (Table 2), the Prius Hybrid exhibited a displacement of $1798 \mathrm{cc}$ with an average fuel consumption of $21.3 \mathrm{~km} / \mathrm{L}$ (U.S. EPA announcement) [33,44]. They were lower than the fuel consumption $(17.8 \mathrm{~km} / \mathrm{L})$ for vehicles ranging from 1200 to $1800 \mathrm{cc}$. This shows that fuel consumption and greenhouse gases $/ \mathrm{CO}_{2}$ emission improve as a result of output power reduction and technical innovation.

Table 2. The tested values of fuel consumption (USA Standard: FTP-75). Source [44].

\begin{tabular}{cccccc}
\hline \multirow{2}{*}{ Displacement (cc) } & \multicolumn{5}{c}{ Range Level (Fuel consumption: km/L) } \\
\cline { 2 - 6 } & Level 5 & Level 4 & Level 3 & Level 2 & Level 1 \\
\hline$\leq 1200$ & $\leq 16.1$ & $16.2-18.1$ & $18.2-20.1$ & $20.2-22$ & $\geq 22.1$ \\
\hline $1200 \sim 1800$ & $\leq 12.9$ & $13.0-14.6$ & $14.7-16.1$ & $16.2-17.7$ & $\geq 17.8$ \\
\hline $1800 \sim 2400$ & $\leq 11.3$ & $11.4-12.8$ & $12.9-14.1$ & $14.2-15.5$ & $\geq 15.6$ \\
\hline $2400 \sim 3000$ & $\leq 9.9$ & $10.0-11.2$ & $11.3-12.4$ & $12.5-13.6$ & $\geq 13.7$ \\
\hline $3000 \sim 3600$ & $\leq 9.1$ & $9.2-10.3$ & $10.4-11.4$ & $11.5-12.5$ & $\geq 12.6$ \\
\hline $3600 \sim 4200$ & $\leq 8.4$ & $8.5-9.5$ & $9.6-10.5$ & $10.6-11.6$ & $\geq 11.7$ \\
\hline $4200 \sim 5400$ & $\leq 7.6$ & $7.7-8.1$ & $8.2-8.9$ & $9.0-9.8$ & $\geq 9.9$ \\
\hline$>5400$ & $\leq 6.9$ & $7.0-7.3$ & $7.4-8.1$ & $8.2-8.8$ & $\geq 8.9$ \\
\hline
\end{tabular}




\section{Conclusions and Recommendation}

This study focuses on technical innovation in a conventional engine and output power that affect fuel consumption and greenhouse gases $/ \mathrm{CO}_{2}$ emissions. Our case analysis and literature review show that technical innovations and sustainable development result in lower fuel consumptions and reduced $\mathrm{CO}_{2}$ emissions without compromising engine performance and power output. The technical innovation of conventional engine (such as the turbocharged EcoBoost engine and the Prius Hybrid) is the key to improve fuel consumption and reduce greenhouse gases and $\mathrm{CO}_{2}$ emission. These innovations enabled Ford Motor Taiwan and Toyota Taiwan to achieve their sustainability target of a $15 \% \mathrm{CO}_{2}$ emission reduction before 2015. In 2013, Ford and Toyota have reduced their car emissions by 19\% and 25\%, respectively $[34,35]$. The results of this study provide managerial insights to other automakers to introduce technical innovations and high-performance vehicles. The study also acts as a stimulus to encourage consumers to cut down greenhouse gases $/ \mathrm{CO}_{2}$ emissions by purchasing vehicles with low fuel consumption and greenhouse gases $/ \mathrm{CO}_{2}$ emissions. With the continuous effort to sustainable development by the producers and consumers, global warming will be reduced, resulting in a higher quality of life for our future generations.

\section{Acknowledgments}

We are thankful to the Ministry of Science and Technology, Taiwan, project No. 103-2218-E-033-002 and No. 103-2221-E-033-055 for sponsoring the research.

\section{Author Contributions}

The author Chao-Wu Chou organized the full manuscript, conducted the literature review, and wrote part of the manuscript. The author Wen-Chih Liao put forward the research idea, discussed the research structure, and gave valuable suggestions to the manuscript. The author Simon Wu collected the technical data from the vendors and institutions and wrote part of the manuscript. The author Hui-Ming Wee contributed to the research structure and research methodology, and revised the full manuscript.

\section{Conflicts of Interest}

The authors declare no conflict of interest.

\section{References}

1. Hsiang, S.M.; Burke, M.; Miguel, E. Quantifying the influence of climate on human conflict. Science 2013, 341, 1212-1226.

2. Lamb, H.H. Climate, History and the Modern World, 2nd ed.; Routledge: London, UK, 2002.

3. Hepbasli, A. A key review on exegetic analysis and assessment of renewable energy resources for a sustainable future. Renew. Sustain. Energy Rev. 2008, 12, 593-661.

4. Martin, N.J.; Rice, J.L. Developing renewable energy supply in Queensland, Australia: A study of the barriers, targets, policies and actions. Renew. Energy 2012, 44, 119-127. 
5. Wee, H.M.; Yang, W.H.; Chou, C.W.; Padilan, M.V. Renewable energy supply chains, performance, application barriers and strategies for further development. Renew. Sustain. Energy Rev. 2012, 16, 5451-5465.

6. Bañosa, R.; Manzano-Agugliarob, F.; Montoyab, F.G.; Gila, C.; Alcaydeb, A.; Gómezc, J. Optimization methods applied to renewable and sustainable energy: A review. Renew. Sustain. Energy Rev. 2011, 15, 1753-1766.

7. Root, T.L.; Price, J.T.; Hall, K.R.; Schneider, S.H.; Rosenzweig, C.; Pounds, J.A. Fingerprints of global warming on wild animals and plants. Nature 2003, 421, 57-60.

8. Vitousek, P.M. Beyond global warming: Ecology and global change. Ecology 1994, 75, 1861-1876.

9. Cox, P.M.; Betts, R.A.; Jones, C.D.; Spall, S.A.; Totterdell, I.J. Acceleration of global warming due to carbon-cycle feedbacks in a coupled climate model. Nature 2000, 408, 184-187.

10. United Nations. Kyoto Protocol to the United Nations Framework Convention on Climate Change. Available online: http://unfccc.int/essential_background/kyoto_protocol/items/1678.php (accessed on 15 March 2015).

11. Feroz, E.H.; Raab, R.L.; Ulleberg, G.T.; Alsharif, K. Global warming and environmental production efficiency ranking of the Kyoto Protocol nations. J. Environ. Manag. 2009, 90, 1178-1183.

12. Dovìa, V.G.; Friedlerb, F.; Huisinghc, D.; Klemešd, J.J. Cleaner energy for sustainable future. J. Clean. Prod. 2009, 17, 889-895.

13. Hansen, J.E.; Houghton, J. Global Warming: The Complete Briefing, 3rd ed.; Cambridge University Press: Cambridge, UK, 1998.

14. Union of Concerned Scientists (UCS). Climate Hot Map of Global Warming Effects Around the World. Available online: http://www.climatehotmap.org (accessed on 3 March 2015).

15. Lallanilla, M. What is the Greenhouse Effect? Available online: http://www.livescience.com/ 37743-greenhouse-effect.html (accessed on 3 March 2015).

16. Panwar, N.L.; Kaushik, S.C.; Kothari, S. Role of renewable energy sources in environmental protection: a review. Renew. Sustain. Energy Rev. 2011, 15, 1513-1524.

17. Hodhe, H. A comparison of the contribution of various gases to the greenhouse effect. Science 1990, 248, 1217-1219.

18. Robertson, G.P.; Paul, E.A.; Harwood, R.R. Greenhouse gases in intensive agriculture: Contributions of individual gases to the radioactive forcing of the atmosphere. Science 2000, 289, 1922-1925.

19. Harabi, N. Appropriability of technical innovations: An empirical analysis. Res. Policy 1995, 24, 981-992.

20. Gort, M.; Klepper, S. Time paths in the diffusion of product innovations. Econ. J. 1982, 92, 630-653.

21. Shah, A.; Lennström, D.; Sturesson, P.; Easterling, W. NVH integration of twin charger direct injected gasoline engine. SAE Int. J. Passeng. Cars Mech. Syst. 2014, 7, 1221-1228.

22. Sclar, D. What Are Hybrid Vehicles? Auto Repair for Dummies, 2nd ed.; John Wiley \& Sons, Inc.: Hoboken, NJ, USA, 2014.

23. Wang, X.M.; He, H.W.; Sun, F.C.; Zhang, J.L. Application study on the dynamic programming algorithm for energy management of plug-in hybrid electric vehicles. Energies 2015, 8, $3225-3244$. 
24. Lund, H. Renewable energy strategies for sustainable development. Energies 2007, 32, 912-919.

25. Robinson, J.B.; Herbert, D. Integrating climate change and sustainable development. In Proceedings of the IPCC Expert Meeting, Colombo, Sri Lanka, 27-29 April 1999; pp. 143-162.

26. Smit, B.; Pilifosova, O. Adaptation to climate change in the context of sustainable development and equity. In Climate Change 2001: Impacts, Adaptation and Vulnerability; McCarthy, J.J., Canziani, O., Leary, N.A., Dokken, D.J., White, K.S., Eds.; Cambridge University Press: Cambridge, UK; 2001; pp. 877-912.

27. Frasera, E.D.G.; Dougilla, A.J.; Mabeeb, W.E.; Reeda, M.; McAlpinec, P. Bottom up and top down: Analysis of participatory processes for sustainability indicator identification as a pathway to community empowerment and sustainable environmental management. J Environ. Manag. 2006, 78, 114-127.

28. Burton, I. Report on reports: our common future: The world commission on environment and development. Environ. Sci. Policy Sustain. Dev. 1987, 29, 25-29.

29. Schalteggera, S.; Synnestvedtb, T. The link between 'green' and economic success: environmental management as the crucial trigger between environmental and economic performance. J. Environ. Manag. 2002, 65, 339-346.

30. Butler, M.A.; King, A.A. Phylogenetic comparative analysis: A modeling approach for adaptive evolution. Am. Nat. 2004, 164, 683-695.

31. Ragin, C.C. The Comparative Method: Moving Beyond Qualitative and Quantitative Strategies; University of California Press: Berkeley, CA, USA, 1987.

32. Stojanovic, V.; Oklobdzija, V.G. Comparative analysis of master-slave latches and flip-flops for high-performance and low-power systems. IEEE J. Solid-State Circuits 1999, 34, 536-548.

33. Environmental Protection Administration Taiwan (EPA). Green Car Guidance. Available online: http:/greencar.epa.gov.tw/greencar.aspx (accessed on 3 May 2015). (In Chinese)

34. Ford Lio Ho (FLH). Ford Turbocharged EcoBoost Engine. Available online: http://www.ford.com. tw/techsection\#fullscreen-overlay=cid=1249087333469 (accessed on 3 May 2015). (In Chinese)

35. Hotai Motor Co., Ltd. Toyota Prius Hybrid Vehicle. Available online: http://www.toyota.com.tw/ tech/ultimate_eco_car_parallax/Ultimate_Eco_Car (accessed on 3 May 2015). (In Chinese)

36. Yulon Motors (Nissan). Active Fuel Management (AFM). Available on line: http://www.yulon-motor. com.tw/car/tech_detail.asp?CTID $=\{8 \mathrm{~A} 63 \mathrm{~B} 62 \mathrm{~F}-1008-4225-98 \mathrm{E} 7-5 \mathrm{D} 048322263 \mathrm{~A}\} \quad$ (accessed on 3 May 2015). (In Chinese)

37. China Motor Co., Ltd. (CMC). Mitsubishi Innovative Valve Timing Electronic Control System. Available online: http://www.china-motor.com.tw/innovate/innovate_04_1.html (accessed on 3 May 2015). (In Chinese)

38. Honda Taiwan. Honda Variable Cylinder System (VCM). Available online: http://www. honda-taiwan.com.tw/auto/technology_VCM.html (accessed on 3 May 2015). (In Chinese)

39. Industrial Technology Research Institute (ITRI). The Estimation Results of Fuel Consumption and $\mathrm{CO}_{2}$ Emission; The Technical Data of Industrial Technology Research Institute, Chutung, Hsinchu, Taiwan, 21 October 2014. (In Chinese).

40. The Auto Channel. Toyota and Lexus Hybrids Top One Million Sales in the U.S. Available online: http://www.theautochannel.com/news/2009/03/11/453029.html (accessed on 3 May 2015). 
41. Toyota Motor Corporation (TMC). Worldwide Prius Sales Top 3 Million. Available online: http://newsroom.toyota.eu/print.do;jsessionid=A753569EFEA6BFD862CD0130EA70FFBE?\&id =3515 (accessed on 3 May 2015).

42. Toyota Motor Corporation (TMC). Worldwide Sales of Toyota Hybrids Top 6 Million Units. Available online: http://corporatenews.pressroom.toyota.com/releases/worldwide+toyota+hybrid+ sales+top+6+million.htm (accesses on 3 May 2015).

43. Department of Energy (DOE). EPA's Top 10 Conventionally-Fueled Vehicles for Model Year 2013. Available online: http://energy.gov/eere/vehicles/fact-765-february-4-2013-epas-top-10conventionally-fueled-vehicles-model-year-2013 (accessed on 3 March 2015).

44. Auto Energy Website (AEW). Vehicle Energy Consumption Modelling and Analysis. Available online: https://auto.itri.org.tw/mode.htm (accessed on 3 March 2015). (In Chinese)

(C) 2015 by the authors; licensee MDPI, Basel, Switzerland. This article is an open access article distributed under the terms and conditions of the Creative Commons Attribution license (http://creativecommons.org/licenses/by/4.0/). 